\title{
Knee Extensor Strength Prediction Formula Using Modified Aneroid Sphygmomanometer in Healthy Female Adults
}

\author{
Erik Setiawan, Marietta Shanti Prananta, Novitri \\ Department of Physical Medicine and Rehabilitation, Faculty of Medicine, Universitas Padjadjaran-Dr. Hasan \\ Sadikin General Hospital, Bandung
}

\begin{tabular}{|c|c|}
\hline Abstract & $\begin{array}{l}\text { Objective: To discover isometric knee extensor muscle strength prediction } \\
\text { formula using hand-held dynamometer (HHD) through the use of modified } \\
\text { aneroid sphygmomanometer (MAS). Isometric knee extensor muscle strength } \\
\text { examination is required to diagnose and evaluate the treatment of quadriceps } \\
\text { femoris weakness. }\end{array}$ \\
\hline & $\begin{array}{l}\text { Methods: This was a quantitative observational and correlational analysis } \\
\text { study with cross-sectional design. Isometric knee extensor muscle strength } \\
\text { was measured using HHD and MAS with } 60^{\circ} \text { knee flexion in sitting position. } \\
\text { Correlation tests were performed to investigate the correlation between } \\
\text { HHD, MAS, and other variables. Regression test was carried out to analyze } \\
\text { knee extensor strength regression using HHD through MAS. }\end{array}$ \\
\hline & $\begin{array}{l}\text { Results: Subjects enrolled were } 25 \text { healthy females aged } 23-52 \text { years old. The } \\
\text { correlation between HHD and MAS was significant while age, body weight, } \\
\text { body height, and body mass index (BMI) did not show correlation with HHD } \\
\text { and MAS. The isometric knee extensor muscle strength using HHD could be } \\
\text { predicted by formula }=0.1041 \text { xMAS. }\end{array}$ \\
\hline $\begin{array}{l}\text { Received: } \\
\text { July } 19,2017\end{array}$ & $\begin{array}{l}\text { Conclusions: Isometric knee extensor muscle strength measured using HHD } \\
\text { strongly correlates with that of using MAS with } 60^{\circ} \text { knee flexion in sitting } \\
\text { position and can be predicted from measurement values of MAS. The formula } \\
\text { is only suitable for females. }\end{array}$ \\
\hline $\begin{array}{l}\text { Revised: } \\
\text { December 22, } 2017\end{array}$ & $\begin{array}{l}\text { Keywords: Hand-held dynamometer, knee extensor, prediction formula, } \\
\text { sphygmomanometer }\end{array}$ \\
\hline $\begin{array}{l}\text { Accepted: } \\
\text { February 26, } 2018\end{array}$ & $\begin{array}{l}\text { pISSN: 2302-1381; eISSN: 2338-4506; http://doi.org/10.15850/ijihs.v6n1.1103 } \\
\text { IJIHS. 2018;6(1):48-55 }\end{array}$ \\
\hline
\end{tabular}

\section{Introduction}

Measurements of muscle strength become the basic components of the physical examinations commonly associated with physical medicine and rehabilitation study. The measurements of muscle strength appropriate for application in clinical practices can be performed using a manual muscle testing (MMT) and hand-held dynamometer (HHD).1-3

Manual muscle testing is commonly used in clinical settings for screening muscle strength; however, it is subjective and less sensitive. On Correspondence:

Erik Setiawan, Department of Physical Medicine and Rehabilitation, Faculty of Medicine,

Universitas Padjadjaran-Dr. Hasan Sadikin General

Hospital, Bandung

Jl. Pasteur No. 38, Bandung, Indonesia

e-mail: dr.eriksetiawan@gmail.com the other hand, HHD is able to give objective results and also more sensitive than the MMT; therefore, it is more suitable to be used for diagnosing weakness in quadriceps femoris muscle and for the post-treatment evaluation of the muscle. However, its high price becomes a major limitation, especially for developing countries, that the HHD is currently not widely available and is rarely used in rehabilitation clinics in Indonesia. ${ }^{3-9}$

Modified aneroid sphygmomanometer, or MAS, is an alternative method for measuring muscle strength with a lot of advantages, such as its affordable price, wide availability, and objective assessment results. Measurements using MAS are quick and and can be repeated with consistent results. There are several MAS methods used in several studies with the bag method as the most common method as it is 
easier to stabilize and gives more consistent results. ${ }^{10-13}$

Most of the studies done in the past assumed the $90^{\circ}$ knee flexed in sitting position in order to assess the isometric knee extensor muscle strength. ${ }^{7,9,14}$ This posture is disadvantageous for quadriceps femoris muscle because the muscle is not in its optimal length considering its length-tension relationship and moment arm length. The maximum isometric knee extensor strength is peaked around $60^{\circ}$ of knee flexion. Hence, this study was performed using $60^{\circ}$ knee flexed position. ${ }^{2,15}$

Despite the fact that HHD has become the gold standard for evaluating muscle strength in clinical settings, its limited availability in developing countrybecomes a major limitation; while aneroid sphymomanometer is widely available and its modification is reversible and easy to do. This study aimed to explore knee extensor muscle strength prediction formula using HHD from measurement using MAS with bag method in healthy adult subjects.

\section{Methods}

This study was a quantitative observational and correlational study using cross-sectional design to explore the correlation and regression of isometric knee extensor muscle strength measured using HHD and MAS in healthy adults. The sampling method used in the study was consecutive sampling. The minimum sample of this study was 25 subjects. The subjects were people who worked at the Department of Physical Medicine and Rehabilitation, Faculty of Medicine, Universitas Padjadjaran-Dr. Hasan Sadikin General Hospital, Bandung.

The inclusion criteria for this study were 20-59 years old subjects, capable of following instructions well, have a full range of motion of knee flexion of dominant leg, and was willing to participate in the study, proven by signing the informed consent. The exclusion criteria were neuromuscular or musculoskeletal disorders on the dominant leg; uncontrolled high blood pressure and metabolic disease; a history of heart disease; and suffering from rheumatic or degenerative joint diseases on the dominant leg. The subjects would be excluded if the MAS measurement results were over the maximum scale range of $>300 \mathrm{mmHg}$ because it was not possible to read the objective data in this condition thus the data cannot be included in the analysis.

The instruments used in this study were baseline analog push-pull dynamometer (with continuous dial that holds maximum force readings), Fujito aneroid sphygmomanometer, a cotton bag sewn on the edge to contain the rubber sphygmomanometer cuff, and NK table with modified shin pads. The shin pads were modified so that the angle of the subjects' knee would be the same as the torque arms when the leg being examined was placed in front of

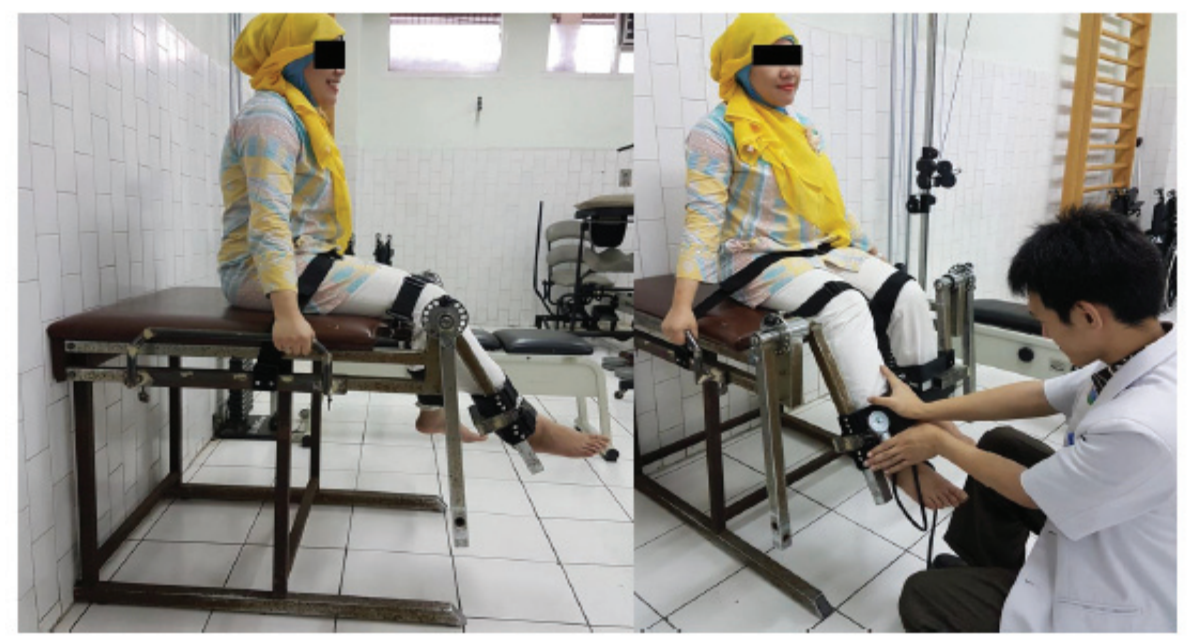

Fig. 1 Subject's Positioning \& Stabilization. Subject was in Upright Sitting Position while Holding the Railings and Examined Knee in $60^{\circ}$ Flexion with Straps on Pelvis, Thighs, and Shins (Left). Stabilization of MAS by the Examiner (Right) 
the shin pads (Fig. 1).

The adaptation of the bag method was then performed by first removing the outer velcro of the sphygmomanometer cuff, then folded the rubber part of the cuff into three equal parts followed by inserting it into a cotton bag with zipper (Fig. 2). Before it could be used, the cuff was inflated to $100 \mathrm{mmHg}$ and the valve was kept closed to remove the folds from the inflatable portion, then the pressure was reduced to $20 \mathrm{mmHg}$ and the valve was closed again to prevent leakage. Hence, the measurement range became 20-300 $\mathrm{mmHg}$. After this adaptation, the size of the cuff was $11.5 \mathrm{~cm}$ long, $6.5 \mathrm{~cm}$ wide, and $6 \mathrm{~cm}$ thick. ${ }^{10}$

Data were collected by one male examiner with a normal body mass index (BMI) level. The examiner was already familiar with the equipment. The examiner sat on a fixated chair during the measurements so that he was able to hold the examined leg of the male and female subjects without making any movement. The use of one examiner to hold the subjects' legs while stabilizing the equipment, as well as to read the dial and to record the results was to simulate clinical settings.

Subjects who met inclusion criteria were given information about the objective of the study and data collection techniques used. The subjects then signed the informed consent form if they agreed to participate. The inclusion and exclusion criteria were determined from the anamnesis and physical examination by a senior Physical Medicine and Rehabilitation resident doctor. Subjects' basic data were then collected: age, sex, side of dominant leg, body weight, and body height.

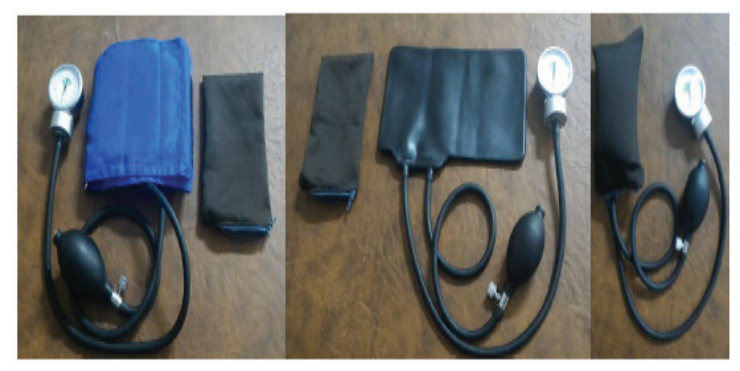

Fig. 2 Bag Method Modification of Aneroid Sphygmomanometer. Sphygmomanometer before Modification and the Cotton Bag (Left). Outer Velcro of Sphygmomanometer Cuff was Removed (Middle). Cuff was Inserted into the Bag and was Inflated (Right)
The next step was measurements of knee extensor muscle strength of the dominant leg using a push-pull dynamometer. Subjects were instructed to sit on NK table with the popliteal region adhere to the edge of the table (Fig. 1). The examined leg was placed in front of the modified shin pad with the torque arm fixated at $60^{\circ}$ of knee flexion, while the unexamined leg was placed behind the shin pad on the other side. The fixation strap was placed on the subjects' lower leg, thigh, and hip. Subjects were instructed to maintain an upright position and used both hands to hold the railings on the side of the table to fixate the trunk. The examiner then placed the pushpull dynamometer slightly above ankle joint perpendicular to the lower leg. Then subjects were asked to push his examined leg forward gradually until maximum force in 5 seconds and the examiner hold the dynamometer to prevent any movement (make test). Maximum isometric contraction strength that was shown in the HHD was the strongest muscle strength acquired directly before the leg moved. The initial measurements were performed to make subjects familiar with the devices (data were not taken). Measurements were then repeated three times with a 30 seconds rest to prevent fatigue which might be experienced by both subjects and examiner. The results were then recorded in examination form.

Measurements of knee extensor muscle strength of the dominan leg using MAS with bag method required the same posture and fixation straps of subjects as those using HHD. The bag was inflated to $100 \mathrm{mmHg}$ and reduced to $20 \mathrm{mmHg}$ as preparation before each measurements. The examiner placed the bag slightly above ankle perpendicular on the leg (Fig. 1). The examiner maintained flat hands on the bag surface contact area and avoided grasping the bag. The dial aneroid reading was placed perpendicular to examiner's eyes so that there was no deviation in reading the result. The instructions given to subjects and protocols to collect data were as same as those using HHD.

Data were then analyzed using statistical tests, including normality data test, descriptive statistics, and, depending on data distribution, Pearson and/or Spearman correlation test, as well as regression test. The regression test was used for prediction formula of isometric knee extensor muscle strength from examination result using MAS.

Average from the three results of muscle strength measurement using HHD and MAS of each subject were calculated so that every 
Table 1 Subjects' Characteristic Data

\begin{tabular}{lcccc}
\hline \multicolumn{1}{c}{ Variables } & Mean $( \pm \mathbf{S D})$ & Median (Range) & W & p Value \\
\hline Age $($ years $)$ & & $33(23-52)$ & 0.8486 & 0.001 \\
Weight $(\mathrm{kg})$ & $56.12( \pm 12.34)$ & & 0.9935 & $0.1098^{*}$ \\
Height $(\mathrm{cm})$ & $156.60( \pm 6.63)$ & & 0.9597 & $0.1532^{*}$ \\
BMI $\left(\mathrm{kg} / \mathrm{m}^{2}\right)$ & $22.80( \pm 4.30)$ & & 0.9314 & $0.0901^{*}$ \\
HHD $(\mathrm{kg})$ & & $29.83(24.50-33.83)$ & 0.8994 & 0.0174 \\
MAS $(\mathrm{mmHg})$ & $283.23( \pm 10.92)$ & & 0.9440 & $0.1920^{*}$ \\
\hline
\end{tabular}

Note: $\mathrm{BMI}=$ body mass index, $\mathrm{HHD}=$ hand-held dynamometer, MAS=modified aneroid sphygmomanometer $*$ p-value $>0.05$ means normal distribution

subject had one HHD mean value (HHD variable) and one MAS mean value (MAS variable). The HHD and MAS variables were then included in the normality data test along with age, weight, height, and BMI variables.

Normality of data were tested to determine the data distribution. If data were distributed normally, the correlation test used would be Pearson and if the data were not distributed normally, Spearman test was selected as the correlation test. For both tests, the confidence interval used was confidence interval (CI) 95\% or alpha 0.05 . If the results showed a significant correlation, analysis would be continued with regression test with forward step-wise method to predict isometric knee extensor muscle strength using HHD from measurement results using MAS. Residual test was then performed to ensure that the prediction formula resulting from the regression test were valid.
This study was conducted at the Department of Physical Medicine and Rehabilitation of the Faculty of Medicine, Universitas PadjadjaranDr. Hasan Sadikin General Hospital, Bandung in December 2015-February 2016. It was approved by Health Research Ethic Committee, Faculty of Medicine, Padjadjaran University (ethical exemption letter no: 727/UN6.C1.3.2/ KEPK/PN/2015). The study was commenced after receiving approval. All subjects' data and information were confidential.

\section{Results}

Fifteen of 40 subjects, all males, were excluded because their objective data measurements were over the maximum scale of MAS ( $>300$ $\mathrm{mmHg}$ ) that the objective data cannot be read. The subjects included in data analysis were 25

Table 2 Spearman Correlation Test between Knee Extensor Muscle Strength Measurement Results and Other Variables

\begin{tabular}{lccc}
\hline \multicolumn{1}{c}{ Variables } & $\mathbf{R}$ & $\mathbf{t}(\mathbf{N}-2)$ & p Value \\
\hline HHD and age & 0.1745 & 0.8497 & 0.4043 \\
HHD and weight & 0.2023 & 0.9905 & 0.3322 \\
HHD and height & 0.2263 & 1.1144 & 0.2766 \\
HHD and BMI & 0.1409 & 0.6827 & 0.5016 \\
HHD and MAS & 0.5931 & 3.5332 & $0.0018^{*}$ \\
MAS and age & 0.3112 & 1.5706 & 0.1299 \\
\hline
\end{tabular}

Note: $\mathrm{HHD}=$ hand-held dynamometer, MAS=modified aneroid sphygmomanometer, BMI=body mass index

* p-value was significant 
healthy females.

The subjects' characteristic data were presented in the study (Table 1). The median age of the subjects was 33 years old with 23 to 52 years old range. The means for body weight, body height, and BMI were 56.12 \pm 12.34 $\mathrm{kg}, 156.6 \pm 6.63 \mathrm{~cm}$, and $22.80 \pm 4.30 \mathrm{~kg} / \mathrm{m}^{2}$, respectively.

The 3 trials of measurements using HHD ranged between $24.5-33.83 \mathrm{~kg}$ with a median of $29.83 \mathrm{~kg}$. The mean of MAS variables were $283.23 \pm 10.92 \mathrm{mmHg}$. The results of normality test using Shapiro Wilk test showed that body weight, body height, BMI, and measurement value using MAS were normally distributed. However, the subjects' characteristics data of age and measurement value using HHD were not normally distributed $(\mathrm{p}<0.05)$.

Results of Spearman correlation analysis (CI $95 \%$ or alpha 0.05 ) between the measurement values using $\mathrm{HHD}$, the measurement values using MAS, and other variables that were not normally distributed are presented (Table 2). The results of Pearson correlation analysis (CI $95 \%$ or alpha 0.05 ) between measurement values using MAS as well as other variables that were normally distributed were 0.3086 ; $\mathrm{p}=0.133$ for MAS and body weight, 0.3740 ; $\mathrm{p}=0.065$ for MAS and body height, and 0.2099 ; $\mathrm{p}=0.314$ for MAS and BMI.

The only significant correlation discovered in the study was the correlation between measurement values using HHD and using MAS ( $p=0.0018)$ (Table 2). The correlations between measurement values using HHD and age, HHD and body weight, HHD and body height, as well as HHD and BMI were not significant ( $p>0.05)$. The correlations between measurement values using MAS and age, MAS and body weight, MAS and body height, as well as MAS and BMI were also not significant $(\mathrm{p}>0.05)$.

The regression analysiswascarried outusing forward step-wise method with independent variables included in the analysis were age, weight, height, BMI, and measurement value using MAS, while dependent variable was the measurement values using HHD. The variable taken into regression after the analysis was only the measurement values using MAS. The contribution of measurement value using MAS was $99.62 \%$. This variable had a significant regression coefficient to predict value of knee extensor muscle strength using HHD with $\mathrm{R}=0.996$. Age, weight, height, and BMI were not taken into regression because MAS variable by itself had a very strong correlation (99.62\%) with the HHD variable so that other variables becomes insignificant in the formula.

The regression formula was discovered to predict knee extensor muscle strength value using HHD in healthy adults is as follows: prediction value of the knee extensor muscle strength using HHD was equal to $0.1041 \mathrm{x}$ knee extensor muscle strength value using MAS. This prediction formula was only suitable for females.

Residual test was then conducted to analyze whether the regression formula was valid to be used as a predictor. The requirements for a regression formula to be considered valid to be used as a prediction formula are residue is normally distributed and mean residue $=0$. Normality test using the Shapiro Wilk showed $\mathrm{W}=0.934$ and $\mathrm{p}=0.11$, meaning that the residue was distributed normally. The result of residual test was mean residue $=-0.033$ (SD \pm 2.633 ). $T$ count $=-0.063$, meaning that the $\mathrm{p}$ value $>0.05$, showing that mean residue $=0$. As the requirements of residual test had already been fulfilled, the regression formula could be used to predict knee extensor muscle strength value using HHD through MAS measurement results.

The chart presenting the prediction values of knee extensor muscle strength measurement using HHD from the regression formula to its actual observation values is depicted in (Fig. 3). The observation value is the muscle strength value promptly measured using HHD. Prediction value is the result of prediction formula of $\mathrm{HHD}=0.1041 \mathrm{xMAS}$, meaning that the muscle strength measurement value using MAS times 0.1041 equals the prediction of muscle strength value using HHD. The redlined dash is regression line with CI 95\%.

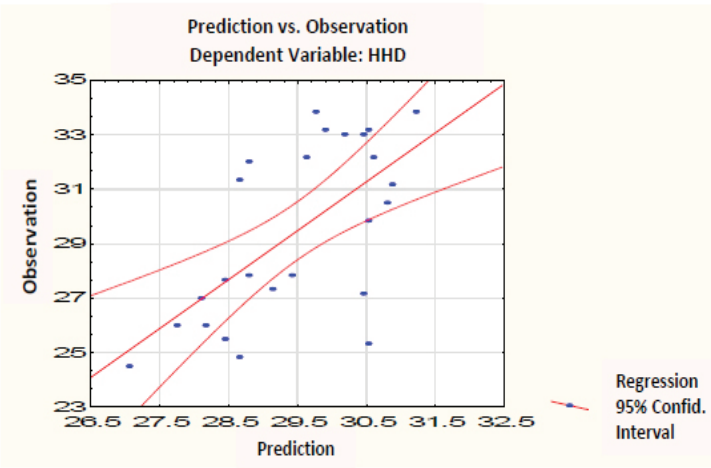

Fig. 3 Correlation between Observation Values and Prediction Values of Knee Extensor Muscle Strength Using Hand-Held Dynamometer 


\section{Discussion}

Most previous studies assessed isometric knee extensor muscle strength, either using HHD or MAS, using sitting posture with $90^{\circ}$ hip and knee flexion..$^{7,9-11,14}$ Other studies used sitting posture with $90^{\circ}$ hip flexion and $45^{\circ}$ knee flexion, supine posture with $30^{\circ}$ knee flexion and prone posture with $90^{\circ}$ knee flexion..$^{5,12,16}$ These postures were less favorable for quadriceps femoris muscles because its not in its optimal length considering its lengthtension relationship and moment arm length. Quadriceps femoris muscles can hold $90 \%$ of its maximum force in $80^{\circ}$ to $30^{\circ}$ knee flexion range. It can produce great force in $80^{\circ}$ knee flexion because the length-tension relationship of vasti muscle are favorable at this angle. This factor combined with the change of patellar moment arm length as knee extends produce even greater quadriceps muscles force. The maximum isometric knee extensor strength is peaked around $60^{\circ}$ of knee flexion. ${ }^{2,15}$

This study is concerned more about the positioning to allow the recording of absolute maximum force output in the isometric knee extensor muscles while still preventing the subjects to overpower the examiner and also preventing difficulties in stabilizing equipment on subjects' legs. The previous studies stated that one of the problems found in isometric knee extensor muscle strength measurement is that the examiners were not able to give proper pressure against subjects' maximum force while stabilizing the equipment on the legs. 5,9,10,14 The use of bag method MAS can help with the problem because it is easier to stabilize. Consistent with Souza et al. ${ }^{10}$ study, examiner could easily stabilize MAS with bag method on subjects' legs while resisting leg movements, but the examination table or the examiner's seat was pushed away during the measurement of stronger subjects. By fixing the examination table and the examiner's seat against the wall, the examined leg could be prevented from moving during examination. Ford-Smith et al. ${ }^{14}$ used steel iron frame fixated to thick carpet to hold HHD, but it is less practical in clinical settings. Katoh ${ }^{9}$ used belt to fixate HHD, but the same modification cannot be used on MAS with bag method because the pressure distribution on the bag might be uneven.

The reason of unreadable data resultsin MAS measurements of stronger subjects according to previous studies were the unability of the examiner to stabilize the equipment when force were given and the modification method of MAS. ${ }^{10-12}$ Although the examiner in this study was able to hold all subjects' legs from moving while stabilizing the equipment when subjects extended their knees, the bag method of MAS limited the readability of data results of stronger subjects. A comparation study of methods used in MAS by Souza et al..$^{10}$ revealed that MAS with permanently sewn bag method had more consistent results compared to the loosely rolled cuff method and was easier to stabilize on subjects' body parts, although the bag method had lower ability to assess muscle strength of stronger subjects. It may be because the bag is more elastic, requires more air in the pre-inflation of the equipment, has larger contact area with the subjects' skin and reaches higher pressure values when an external force is applied.

Moreover, in this study, the $60^{\circ}$ angle of knee flexion in sitting posture provide more advantage to quadriceps femoris muscle group to produce its peak force, rather than the $90^{\circ}$ or $45^{\circ}$ knee flexion in sitting posture, $30^{\circ}$ knee flexion in supine posture, and $90^{\circ}$ knee flexion in prone posture used in the previous studies that were limiting the forces produced by the quadriceps muscle groups that are caused by its mechanical disadvantage and gave more mechanical advantage to the examiner. ${ }^{5,7,9-12,14,16}$ Helewa et $a l^{12}$ who examined knee extensors in supine posture with $30^{\circ}$ of knee flexion using MAS in rheumatoid arthritis subjects did not report any dropped out subjects caused by MAS limitation in data reading.

Isometric knee extensor muscle strength measurement using MAS with bag method may be able to be appropriately used for subjects with weakness in the quadriceps femoris muscle. For comparison, non-adapted sphygmomanometer method presents a better ability to assess stronger subjects, at the cost of greater difficulty for stabilizing the equipment because of its larger surface contact area. This method requires more training to maintain flattened hand on the equipment, otherwise the result will not be reliable. ${ }^{10,11,17}$

Subjects enrolled in this current study only consisted of females. Hence, it was not possible to see the correlation between gender and muscle strength measurement results using HHD and MAS. In general, different sex can influence the individual's muscle strength. Young boys' muscle strength is approximately the same as that of young girls before puberty. After puberty, males continue to increase their muscle strength while there is no change in the muscle strength of females. Sex-related body composition changes account for the muscle 
strength difference. The greater strength of males related primarily by the greater muscle mass they develop after puberty. Before about age 16 , the ratio of lean body mass to whole body mass is similar in males and females. After the puberty, the muscle mass of males becomes $50 \%$ greater than that of females, and the ratio of lean body mass to whole body mass also becomes greater. ${ }^{15,18,19}$

Age range among the subjects in this study was quite wide (23-52 years) that represents adult age. Muscle strength in adult age reaches its maximum strength and size of crosssectional area between the age of 20 and 30 years, then gradually declining after age of 30 years for most of muscle groups. As individuals age, number of motor units decline. However, in this study, age did not correlate with HHD and MAS measurement values. It was not included in the prediction formula because the contribution of the difference of knee extensor strengths between younger and older female adults was not significant, compared to the $99.62 \%$ contribution of MAS variable. With very strong correlation between MAS and HHD variables, other variables became less significant to be included into the prediction formula. ${ }^{15,18,19}$

In this study, body weight, body height, and BMI did not show correlation with knee extensor muscle strength values using either HHD or MAS. It might be because BMI does not show direct correlation with muscle strength. BMI does not consider body's fat and muscle components. Individuals in the same level of BMI may have different muscle \& fat mass distribution. In trained individuals, the BMI may be higher because of bulkier muscle mass which in general will have greater muscle strength. While in obese individuals, higher BMI with larger fat mass, is likely to have great muscle strength. ${ }^{15,18-20}$

There was significant correlation between knee extensor muscle strength measurements using HHD and MAS. The regression analysis with forward stepwise method only included knee extensor muscle strength measurements using MAS with 99.62\% contribution, meaning that the measurements using HHD was very strongly correlated with the measurements using MAS. This finding supports the usage of knee extensor muscle strength measurement using MAS to predict that of using HHD. Souza et al. ${ }^{11}$ who examined in stroke patients found that at least $57 \%$ of the variations in the HHD values, with coefficient of determination ranged between 0.57 and 0.79 , which can be explained by variations in the MAS measures and supported that it is important that the HHD values can be predicted since others have reported that the strength of specific muscles could predict independence in a given functional activity.

This study has rechecked the formula using residual test by comparing the actual results of measurements using HHD and the predicted results of measurements using HHD through the formula. After the requirements for regression equation were fulfilled, the regression equation is valid to be used as predictor. It is noteworthy that the prediction formula was only suitable with females since the subjects enrolled was only females.

In conclusion, there is a strong correlation between the isometric knee extensor muscle strength measurement values using MAS with the bag method and HHD in female healthy adults with $60^{\circ}$ knee flexion in sitting position. The isometric knee extensor muscle strength measured using HHD in female adults can be predicted through that of using MAS. Further studies may be necessary for subjects with neuromusculoskeletal diseases which cause quadriceps femoris muscle weakness. Another study with lower pre-inflation pressure of MAS with bag method may be able to overcome the limitation of measuring isometric knee extensor strength in stronger subjects.

\section{References}

1. Jensen AM, Stevens RJ, Burls AJ. Estimating the accuracy of muscle response testing: two randomised-order blinded studies. BMC Complement Altern Med. 2016;16(1):492-8.

2. Garcia SC, Dueweke JJ, Mendias CL. Optimal joint positions for manual isometric muscle testing. J Sport Rehabil. 2016;24(1):1-13.

3. Iwamoto $\mathrm{K}$, Yoshio $\mathrm{M}$, Takata $\mathrm{Y}$, Kozuka N.

Reliability and validity of standing balance assessment index using a hand-held dynamometer in stroke patients. J Phys Ther Sci. 2016;28(11):3158-61.

4. Wadsworth CT, Krishnan R, Sear M, Harrold J, Nielsen DH. Intrarater reliability of manual muscle testing and hand-held dynamometric muscle testing. Phys Ther. 1987;67(9):1342-7. 
5. Kelln BM, McKeon PO, Gontkof LM, Hertel J. Hand-held dynamometry: reliability of lower extremity muscle testing in healthy, physically active, young adults. J Sport Rehabil. 2008;17(2):160-70.

6. Stark T, Walker B, Philips JK, Fejer R, Beck R. Hand-held dynamometry correlation with the gold standard isokinetic dynamometry: a systematic review. AAPMR. 2011;3(5):472-9.

7. Weng P, Janssen J, Richards JD, Selfe J. Validity of two clinical knee strength assessments compared to the reference standard. IJPR. 2015;3(6):1264-70.

8. Thorborg K, Bandholm T, Holmich P. Hip- and knee-strength assessments using a handheld dynamometer with external belt-fixation are inter-tester reliable. Knee Surg Sports Traumatol Arthrosc. 2012;21(3):550-5.

9. Katoh M, Yamasaki H. Test-retest reliability of isometric leg muscle strength measurements made using a hand-held dynamometer restrained by a belt: comparisons during and between sessions. J Phys Ther Sci. 2009;21(3):239-43.

10. Souza LA, Martins JC, Moura JB, TeixeiraSalmela LF, Paula FVD, Faria CD. Assessment of muscular strength with the modified sphygmomanometer test: what is the best method and source of outcome values? Braz J Phys Ther. 2014;18(2):191-200.

11. Souza LA, Martins JC, Teixeira-Salmela LF, Lara EM, Moura JB, Aguiar LT, et al. Validity and reliability of the modified sphygmomanometer test to assess strength of the lower limbs and trunk muscles after stroke. J Rehabil Med. 2014;46(7):620-8.

12. Helewa A, Goldsmith $\mathrm{CH}$, Smythe HA. The modified sphygmomanometer - an instrument to measure muscle strength: a validation study. J Chron Dis. 1981;34(7):353-61.

13. Martins JC, Teixeira-Salmela LF, Souza LA, Aguiar LT, Lara EM, Moura JB, et al. Reliability and validity of the modified sphygmomanometer test for the assessment of strength of upper limb muscles after stroke. J Rehabil Med. 2015;47(8):697-705.

14. Ford-Smith CD, Wyman JF, Elswick RK, Fernandez T. Reliability of stationary dynamometer muscle strength testing in community-dwelling older adults. Arch Phys Med Rehabil. 2001;82(8):1128-32.

15. Muscle activity and strength. In: Houglum PA, Bertoti DB, editors. Brunnstrom's clinical kinesiology. $6^{\text {th }}$ ed. Philadelphia: F. A. Davis Company; 2012. p. 125-57.

16. Arnold CM, Warkentin KD, Chilibeck PD, Magnus CR. The reliability and validity of handheld dynamometry for the measurement of lower-extremity muscle strength in older adults. JSCR. 2010;24(3):815-24.

17. Azad AK, Nabi G, Shakoor MA, Moyeenuzzaman MD. Role of muscle strengthening exercise on osteoarthritis of the knee joint. JOM. 2011;12(2):120-4.

18. Yahin A, Moeliono MA, Prananta MS. Handgrip strength prediction formula using aneroid sphygmomanometer in elderly. IJIHS. 2016;4(2):47-55.

19. Katch VL, McArdle WD, Katch FI. Essentials of exercise physiology. $4^{\text {th }}$ ed. Baltimore: Lippincott Williams \& Wilkins; 2011.

20. Stone CA, Nolan B, Lawlor PG, Kenny RA. Hand-held dynamometry: tester strength is paramount, even in frail populations. J Rehabil Med. 2011;43(9):808-11. 